\title{
LA CRÍTICA TEXTUAL EN EL COMENTARIO DE TEXTOS GRIEGOS (CON ALGUNOS EJEMPLOS DE EURÍPIDES)
}

\author{
José S. Lasso de la Vega \\ Universidad Complutense de Madrid
}

Nuestros estudiantes de Bachillerato leen —cada vez menos y con menos profundidad- algunos textos de la literatura griega antigua. Los leen impresos en ediciones o Antologías, sin aparato crítico. La letra impresa del libro produce un respeto reverencial, que el lector suele trasladar a la manera con que el original del texto se ha reproducido. Esto le lleva a adoptar una actitud acrítica, incluso ante las erratas del texto y, alguna vez, si el profesor no es demasiado competente, incluso a la defensa de simples erratas tipográficas. Sabido es que éstas aparecen hasta en el texto cuidado con mayor esmero: Eugenio d'Ors contaba de aquel conocido suyo, que tanto empeño había puesto en editar un texto suyo sin ningún desliz, que corrigió e hizo corregir las pruebas de imprenta docenas de veces y que, cuando por fin parecía que el libro veía la luz sin una sola errata de imprenta, le mandó poner el siguiente colofón que salió así compuesto: «Este libro se publica sin eratas".

Algunas indicaciones sobre la historia de la transmisión escrita de los textos griegos y las circunstancias históricas y de todo tipo que se han producido en esa transmisión; algunas referencias a los tipos más frecuentes de faltas que se originan en la copia, a lo largo de una aventura que separa (por quince o por veinticinco siglos) de nosotros a los originales griegos... creo que pueden y deben dárseles a los alumnos en algún momento oportuno. Se convencerán de que es inadmisible pensar que tales textos no han sufrido deterioro en el curso de tan largo viaje. «Las falsas lecciones -escribía Housman, The Classical Papers III, Cambridge, 1972, 1106- no han sido inventadas todas y de una sola vez por un solo malhechor: son el depósito gradual, siglo tras siglo, de 
la ignorancia y de la fantasía». La crítica textual es «la ortopedia racional de los vocablos que el uso del tiempo y la ligereza de los hombres han estropeado" en aquellos textos venerables, y el recurso a la crítica textual es obligatorio, porque obligatoria es la consideración de los errores contenidos en las copias que nos los han transmitido. Hay que persuadir a los alumnos de que la crítica textual es un arte capaz no sólo de restituir en su pureza un texto que sus copias han hecho irreconocible, sino también de aclarar las razones de la infidelidad creciente con la que los testimonios manuscritos lo han oscurecido; capaz, por ello, de abrirles nuevas perspectivas sobre los textos clásicos que leemos en las clases.

¿Cuál de los textos impresos que comentamos en clase no ha acogido, en cualquiera de sus páginas, alguna corrección de filólogo, alguna conjetura? La «emendatio» es, en la práctica, una forma de «recensio». Los humanistas del siglo XV no distinguían entre la colación de los manuscritos y su corrección en caso necesario (cf. E. J. Kenney, The Classical Text, Berkeley, 1974, 25), entre la «emendatio ope codicum» y la "emendatio ex ingenio siue coniectura». Parece haber sido Robortello (1557) el primero en distinguirlas, como nosotros seguimos haciéndolo. Pues bien, justo de este tema, la "emendatio» que, a veces, se hace necesaria, una vez practicadas la «recensio" y la "collatio», me propongo hablarles hoy, con la ayuda de algunos casos prácticos, empleando para tal fin algunas conjeturas propias sobre textos euripideos. Utilizaré unas cuantas entresacadas de algunas notas mías sobre el texto del drama Ifigenía entre los Tauros: se me han ocurrido confrontando dos ediciones críticas recientes: la de J. Diggle (Euripidis Fabulae II, Oxford C.P., 1981) y la de D. Sansone (Euripides. Iphigenia in Tauris, Leipzig, Teubner, 1981). Esta última la considera la crítica como muy conservadora y prudente; en cambio, la edición de Diggle dicen que es harto proclive a la conjetura. Puede que así sea, en términos generales; pero en los casos que yo aquí discuto, mi impresión es que ambos editores pecan por exceso de conservadurismo o por defecto de atrevimiento, que se traduce en la sobreabundancia de las «cruces corruptelae».

Hay quien tiene una idea demasiado desfavorable de los copistas, cree que se equivocan casi siempre $y$, en consecuencia, se considera autorizado a corregir a cada paso. Coniecturae ludibundae, o sea, el juego de las conjeturas, que ha estado de moda en diversas épocas, pues el siglo XIX (también en esto, nuestro más próximo enemigo) no fue el primero ni el que más lo ha practicado. Pero, por otra parte, la certeza de alguna ocurrencia crítica está fuera de toda duda. Por sobrepreciar ( a santo de qué?) la letra de nuestros códices manuscritos, el 
editor no debe renunciar a intentar sanar un texto que, en muchas ocasiones y con absoluta seguridad, es imposible que el autor lo escribiera.

Sobre este tema no voy a extenderme ahora, porque recientemente lo he hecho y, por si fuera poco en una, en dos ocasiones (cf. «Algunas reflexiones sobre la Crítica textual griega» en el vol. col. Actualización científica en Filología griega, Madrid, I.C.E. de la Universidad Complutense, 1984, 145-162, y «El arte de la conjetura (con ejemplos de la tragedia y lírica coral», en el vol. col. La crítica textual y los textos clásicos, Murcia, Publ. de la Universidad, 1986, 43-64).

La buena conjetura debe responder, ante todo, a una probabilidad intrínseca, aunque no responda siempre a la tan traída y llevada «probabilidad paleográfica». En su famoso ensayo «La aplicación de la inteligencia a la crítica textual» (1922), recogido ahora en The Classical Papers III (Cambridge, 1972), 1058-1069, el gran crítico y esclarecido poeta, escribe: «El método paleográfico ha sido siempre la delicia de los principiantes y la burla de los críticos... Pero incluso cuando la paleografía se queda en su lugar propio, como una muchacha de servicio, y no se cree autorizada a darse aires de señora, es ella predispuesta a sobrepreciarse» (o.c. 1065). El texto transmitido puede haber sido modificado o falsificado a plena conciencia: verbigracia, las alteraciones por "pruderie» (cf. R. M. Ogilvie, Greece and Rome, XVIII, 1971, 32 y ss.; K. J. Dover, Illinois Stud. in Class. Phil., II, 1977, 154 y ss.), que censuran inconveniencias u obscenidades. Es claro que, en este campo, valen más la intuición y la capacidad de «diuinatio» que la laboriosidad y el continuado estudio. Siempre ha habido críticos aplicados que han poseído todas las cualidades secundarias del crítico de textos; pero les ha faltado la sagacidad y la pericia adivinatoria, que han poseído no sólo un crítico tan trabajador como Bentley, sino también otro tan perezoso como Porson, por poner dos ejemplos extremos.

Pero dicho lo anterior, huelga insistir en que, en efecto, el malentendido de signos en la escritura (letras, ligaturas, abreviaturas, cifras) y el malentendido de los sonidos («faltas aurales»), pues en toda copia hay un momento de "dictado interior», son las fuentes más corrientes del «lapsus» del copista y no solamente una circunstancia que secundariamente lo favorece, como pretenden ciertos críticos freudianos (con tanta gracia ridiculizados por Sebastiano Timpanaro en un libro ya popular: El lapsus freudiano, Trad. esp. Barcelona, 1977). Pero reitero mi cautela. A veces, en efecto, basta un ligero cambio en una o dos letras para producir una buena conjetura. Pero, otras veces, no, y hay que meter el bisturí más a fondo en la carne del texto enfermo para sanarlo.

Pero en crítica textual, como en casi todo, es más fácil predicar que dar trigo. Que no se diga de mi modesta persona que hago, como crí- 
tico de textos, lo que suelen hacer los críticos taurinos, que jamás saltan al ruedo. Saltaremos, pues, al ruedo, proponiendo algunas correcciones propias. Comenzaré por un caso quizás sencillo de confusión de letras unciales. Asumiendo tres errores de uncial corrientes $(T / \Pi, O / C$ $y \in / O)$ y con una "distinctio» nueva, en

IPH. IN TAUR. 295

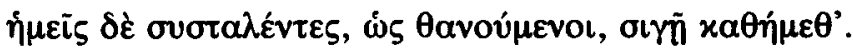

$\theta \alpha$ voú $\mu \varepsilon v o l$ LP, sed suprascr. $\mu \beta$ super av L: $\theta \alpha \mu \beta o u ́ \mu \varepsilon v o \iota$ Seiler et

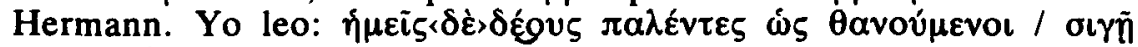
$\varkappa \alpha \theta \dot{\eta} \mu \varepsilon \theta^{\prime}$.

$\theta \alpha \mu \beta \varepsilon ́ \omega$ no se usa en mediopasiva hasta época muy tardía. Si realmente se trata de una corrección (Badham ingeniosamente interpretaba $\mu \beta^{\prime}$ como nota de gramático: $\mu \varepsilon \dot{\lambda} \lambda \omega \nu$ $\left.\delta \varepsilon v ́ \tau \varepsilon \rho o \zeta ~ « f u t u r o ~ s e g u n d o »\right)$, no

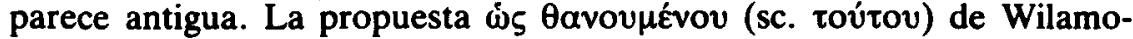
witz (el recogerse en silencio es un gesto típico de respeto al mori-

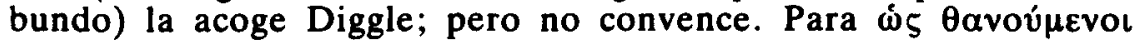

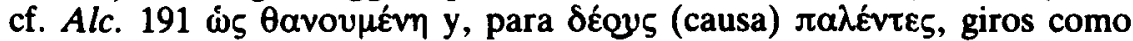

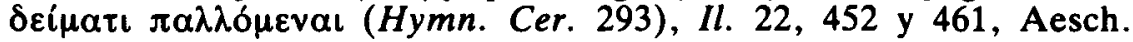
Choeph. 410 etc. La haplografía $\langle\delta \varepsilon\rangle \delta \varepsilon \ldots$, de tipo usual.

También una simple confusión entre dos letras, que con cierta fre-

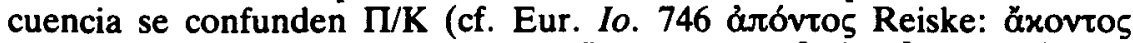

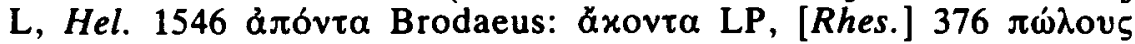

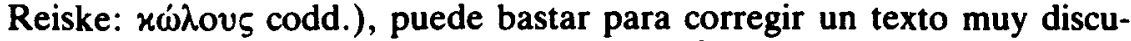
tido sin necesidad (cf. F. A. Paley, Euripides III, Londres, 1880, 38485, y M. Platnauer, Euripides Iphigenia in Tauris, Oxford, 1938, 11112). Se señala la dificultad de xai ov́ en

IPH. IN TAUR. 593

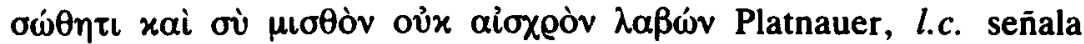
esa dificultad de $x \alpha i$ ov́ (corrupción antigua, pues la tiene ya el papiro $\Pi$ xạ[), que no logran salvar conjeturas hábiles y quizás certeras para arreglar otras partes del difícil texto de estos versos. Se inclina por

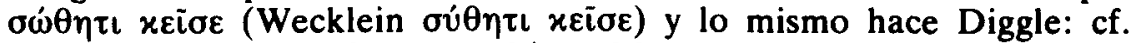

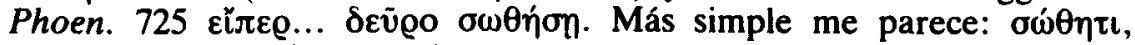
$\pi \alpha i$, $\sigma \dot{v} \mu \iota \sigma \theta \dot{v} v$ oủx... La hermana mayor, $y$ en un momento de afec-

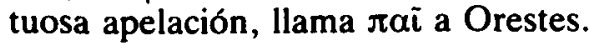


A veces, el error se produce porque, al poner las pausas de lectura en el texto, se han puesto mal o no se han puesto. Hay que empezar por repuntuar el texto. Housman (The Classical Papers I, 56) trataba despectivamente a los editores que casi reducen la crítica de un texto a mera cuestión de comas: virtuosos de las comas que les atribuyen una virtud cabalística que ni siquiera tenía el sello de Salomón. Pero no hay duda de que, para entender un texto escrito, lo primero que debe hacerse es intentar reproducir sus pausas y silencios. Nuestro dramaturgo Jacinto Benavente en Los intereses creados incluye un sabroso diálogo entre Crispín y Polichinela, que viene muy a pelo: Doctor: «Mi previsión se anticipa a todo. Bastará con puntuar debidamente algún concepto...» Ved aquí: donde dice... "Y resultando que si no declaró...", basta una coma y dice: «Y resultando que sí, no declaró...» $Y$ aquí: «Y resultando que no, debe condenársele...", fuera la coma, y dice: "Y resultando que no debe condenársele...». Crispín: « $\mathrm{Oh}$, admirable coma! ¡Maravillosa coma! ¡Genio de la Justicia! ¡Oráculo de la Ley! ¡Monstruo de la Jurisprudencia!».

IPH. IN TAUR. 1134-36

Diggle considera los vv. 1132-36 «locus desperatus» y lo edita entre cruces. M. Platnauer (o.c. 156 piensa que «de la oscuridad de estos tres versos emergen unas pocas claridades»; pero de las cuatro que él enumera, solamente la segunda (que iotía debe mantenerse en un texto

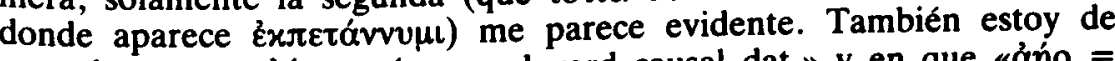
acuerdo en que ỏẹ́ı sería «an akward causal dat.» y en que «áń wind is suspicious»; pero ello no me obliga a considerarlo glosa marginal del verbo; leo áćeı'iotía, uso predicativo de déeı os muy poético

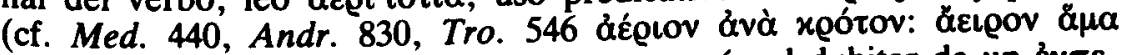
Diggle). Es probable que Platnauer tenga razón al dubitar de un éxлє-

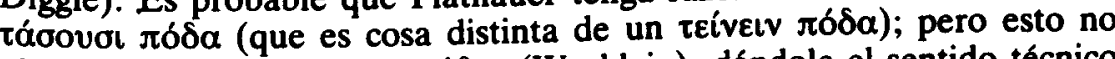
obliga a cambiar $\pi \delta ́ \delta \alpha$ en $\pi \delta ́ \delta \varepsilon \varsigma$ (Wecklein), dándole el sentido técnico náutico (Cf. Liddell-Scott s.u.II 2). Sabida es la afición de Eurípides (que Aristofanes Ran. 97 y ss. ridiculiza) a darle pies a todo ( $\mathrm{Ba} .889$, Alex. fr. 42; Hec. 940 y 1020 etc.). Poniendo coma delante, $\pi \delta ́ \delta \alpha$ vaós puede entenderse como acusativo de aposición. Yo leo:

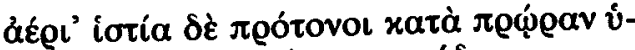

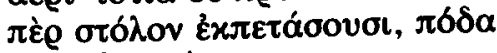

vaò 
"Y por los aires los cables de proa ( garán las velas largándolas (velas que son) el pie de la nave de raudo

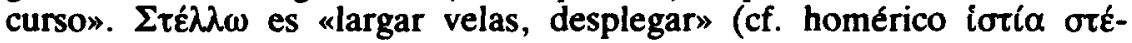

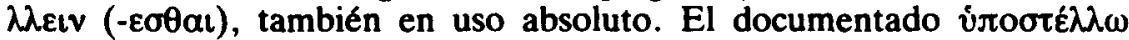
«contraer, quitar vela» (Pínd. I. 2,40) permite suponer un antónimo

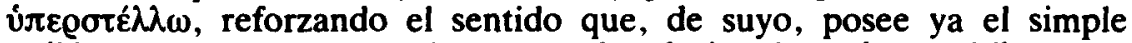

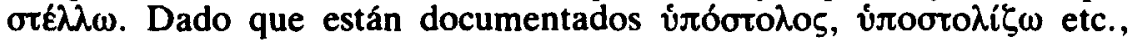
cabría preguntarse si úлદ́

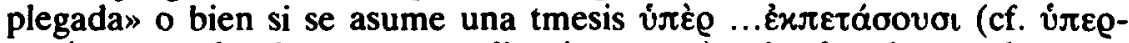

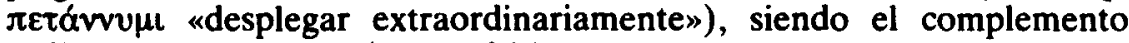

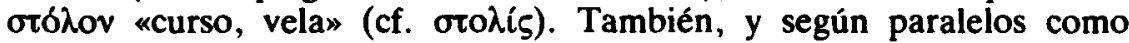

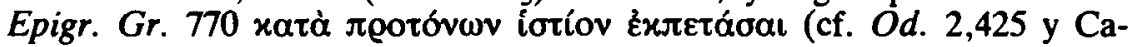

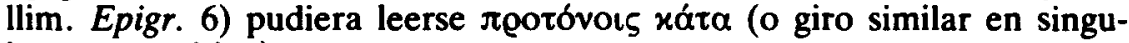
lar o en genitivo):

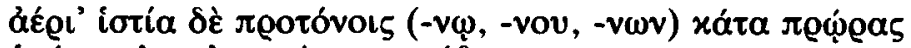

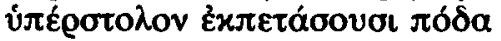
vaòs ف่xvлó $\mu \pi 0 v$

«Y por los aires las velas, contra los cables de proa, el pie a toda

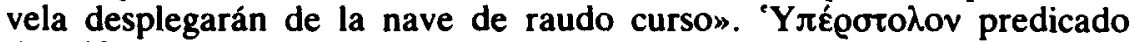
de $\pi \delta \delta \delta \alpha$ en orden normal de palabras. Métrica:

$$
\begin{aligned}
& -v v-v v-v v-v v--5 \text { da}^{--} \\
& \text {v-vv-vv-vv v pros. } \\
& -v-v-- \text { ith. }
\end{aligned}
$$

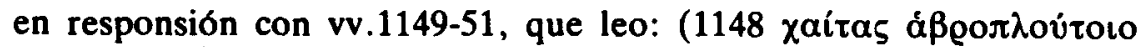
--vv--v pros.).

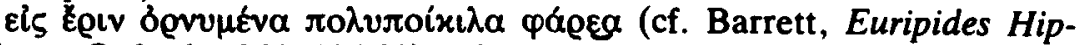
polytos, Oxford, 1964, 125-28) 5 da.

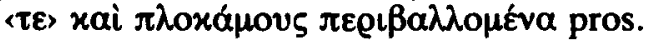

$\gamma E$ Evotv Éoxía\}ov ith.

IPH. IN TAUR. 466

463

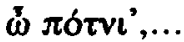

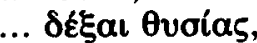

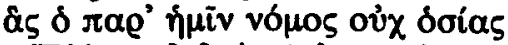

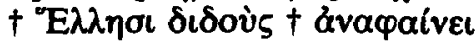




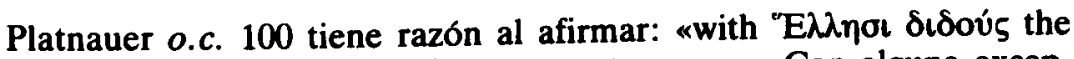
lines are nonsensical». Diggle las pone entre cruces. Con alguna excepción (Grégoire), los editores modernos siguen a Bergk al secluir estas

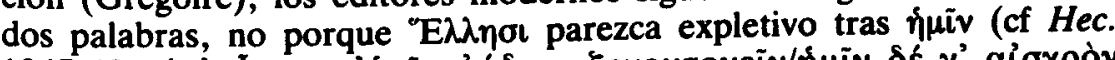

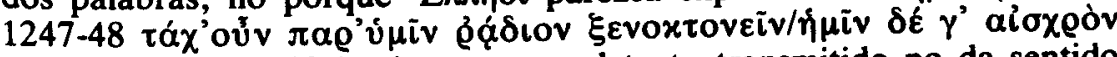

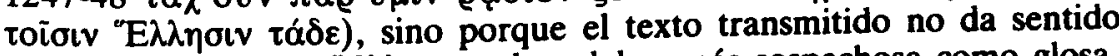
y, puestos a secluir, 'E $2 \lambda \lambda$ ๆr es la palabra más sospechosa como glosa.

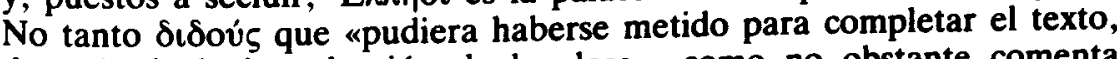
después de la introducción de la glosa», como no obstante comenta Platnauer, l.c. J. Jackson (Marginalia scaenica, Oxford, 1955) propone

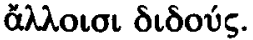

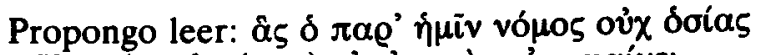

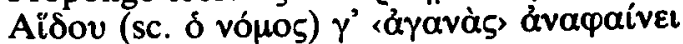

2 an. paroem.

El genitivo adnominal Aídov vale en Eurípides, a veces, con valor

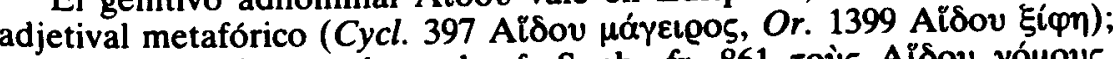

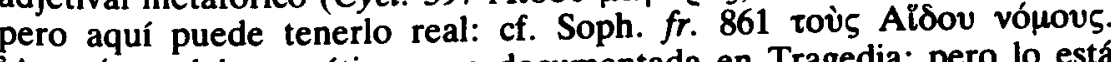
'A yavós, palabra poética poco documentada en Tragedia; pero lo está

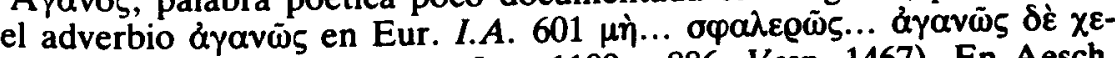
goìv $\mu \alpha \lambda \alpha x \eta \bar{~} \gamma v \omega \dot{\mu} \mu \eta$ (cf. Ar. Lys. 1109 y 886, Vesp. 1467). En Aesch.

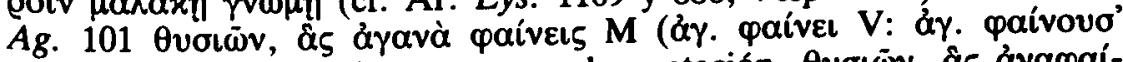

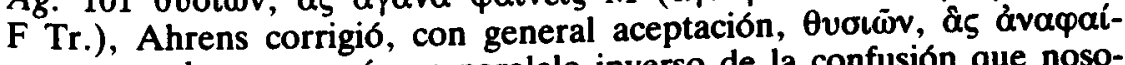
veıs: en todo caso, sería un paralelo inverso de la confusión que nosotros asumimos en el pasaje euripideo, fácilmente explicable por una haplografía en doble dirección:... OY $\triangleleft A \Gamma \rtimes A$ ANAC $>$ ANA... La confusión

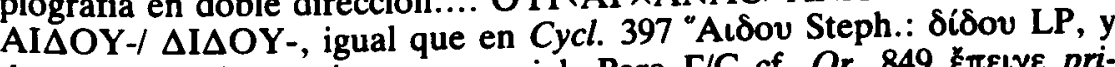
de un tipo $\mathrm{A} / \Delta$ corriente en uncial. Para $\Gamma / \mathrm{C}$ cf. Or. 849 ह $\pi \varepsilon \iota \gamma \varepsilon$ pri-

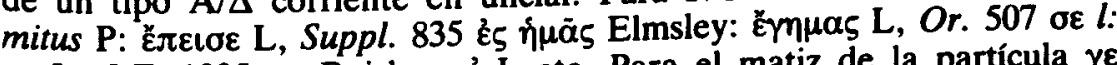

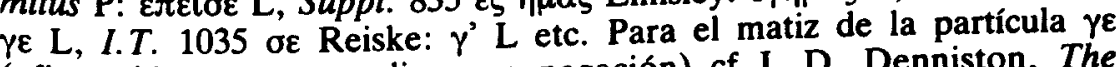
(afirmación que contradice una negación) cf J. D. Denniston, The Greek Particles, Oxford, $1954^{2}, 132$.

«Oh, Señora,... recibe sacrificios, que la ley vigente entre nosotros no píos, pero que la ley del Hades sí revela dulces». Buen sentido, creo, y una corrupción textual cuya explicación permite poner al alcance del alumno nociones muy asequibles: confusión visual de letras unciales parecidas, haplografía («saut du même au même»), concepto elemental de «glosa» e interpolación (para Eurípides, cf. M. D. Reeve «Interpolation in Greek Tragedy» Greek Roman Byz. Stud. XIII 1972, 247-65 y 451-74; XIV 1973, 145-159).

Además de las «faltas serviles» existen las «faltas críticas», los remiendos del filólogo «remendón» que no acierta a adivinar el «hueco de una ausencia». Los ha habido siempre, también en épocas pretéritas, $y$ a veces sus remiendos, por inercia de los editores, se toman casi 
como lecciones auténticas. En principio, para colmar una laguna, hay que recordar que la causa más corriente de la caída de alguna parte del texto es casi siempre «el salto de lo mismo a lo mismo" y que no es aconsejable, para proponer un suplemento, dejarse llevar por las reglas de nuestro propio gusto o por la idea que «a priori» uno se ha formado de las cualidades literarias del autor que edita. Así en

IPH. IN TAUR. ${ }^{428-430}$

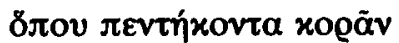

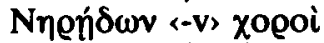

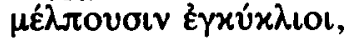

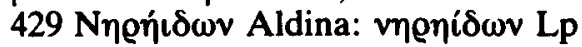

430 Ė $\gamma$ xúx入ı Heath: -íoı LP

La laguna en v. 429 debe corresponder a $-v$ en un $\Lambda$ wil. ----vv- en

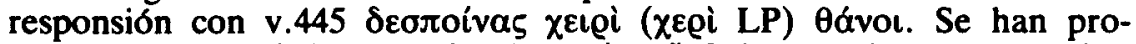

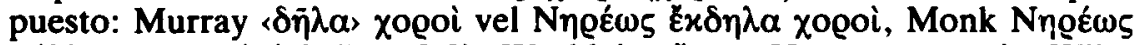

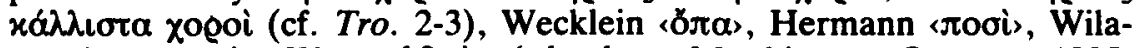

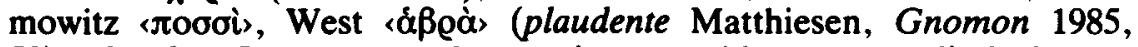
53), alii alia. Como se ve, los caminos seguidos para suplir la laguna han sido: acusativo interno con $\mu \varepsilon \dot{\lambda} \pi \sigma \nu \sigma \mathrm{o}$ ठ $\pi \alpha$, que no da buen metro; cabría pensar en un complemento directo (cf. Ba. 155, Tro. 554, I.T. 221 etc.); también cabrían otras posibilidades, v.s. $\pi \varepsilon v \tau \eta \dot{x} o v \tau \alpha$

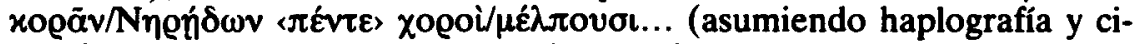
fra $\varepsilon^{\prime}$ : cf. $B a$. 680 y ss. donde cada una de las tres hermanas conduce un coro. Respetando el texto transmitido lo más posible, sin más cam-

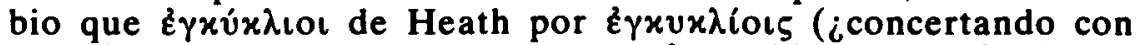

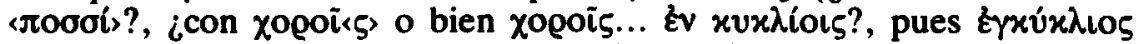

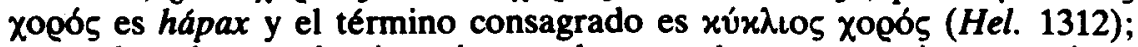
pero el verbo queda sin sujeto, salvo que leamos $\pi \varepsilon v \tau \eta \dot{x o v \tau \alpha ~ x o ́ \varrho \alpha i ~}$

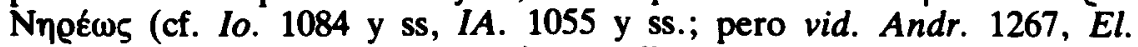
434, Aesch. fr. 174 ( $=285$ Mette) etc.; digo que respetando el texto recibido, salvo ese cambio, también yo me inclino por un acusativo adverbial, y sugiero ‘vøagòs (con sinicesis normal). Nea@ós es vocablo trágico (Esquilo 4 veces, Sófocles 3 veces, aunque con problemas textuales) y «vox Euripidea» (6 veces). Es «fresco, juvenil» y también «nuevo, novedoso", en ambos sentidos aplicado al canto y poesía (cf. Píd. N. 8, 20; Hes. fr. 265, A.P. 7, 13. Cf. gr. tardío vngós «pescado fresco» y gr. mod. tò vegó «agua». Las Nereidas moran en el agua: ergo ningún canto más fresco que el suyo; explicación «etimológica» del 
nombre de los dioses, que usan ya Homero y Hesíodo y es dilecta de los Trágicos: Soph. Ai. 430, fr. 965; Eur. Io. 209, Phoe. 1493, Ba. 367, I.T. 32, Ba. 508, Hel. 13-14, Io. 661-63, Phoe. 26-27 y 636-37, I.A. 321, Rhes. 158, fr. 181 y 517 . Para Esquilo, cf. R. Schweizer-Keller, Vom Umgang des Aischylos mit der Sprache. Interpretationen zu seinen $\mathrm{Na}$ mensdeutungen, Sauerländer Aarau, 1972.

Debo terminar. «La crítica textual -escribe G. Luck, Amer. Journ. Phil. CII 1981, 166 - no es una ciencia exacta; es más bien como el arte de tocar un instrumento musical y requiere buen oído y práctica constante». Es un arte, supone una adecuada combinación de conocimientos y memoria, paciencia de vista y elegancia de mente. Un aforismo médico muy conocido declara que «no existe la enfermedad, existe el enfermo». También en la crítica de textos, como parece que gustaba repetir el filólogo belga Bidez, «todos los casos son especiales». Y la intuición del «caso por caso» es un arte, más que una ciencia. La comparación entre el cirujano y el crítico de textos tiene larga prosapia. Nuestro Saavedra Fajardo la supo explotar con verdadera gracia en su República literaria (cito por la edición de Madrid, Rivadeneyra, 1866, p. 405): «En una calle vi que por la una y otra parte corrían tiendas de barberos, y admirado, pregunté a Marco Varrón la causa por que había tantos de aquel oficio en una república de hombres dotos, que afectaban dejar crecidas las barbas y cabellos. Rióse mucho, y respondióme: No son barberos, sino críticos, cierta especie de cirujanos que en esta república hacen profesión de perficionar 6 remendar los cuerpos de los autores. A unos pegan narices, a otros ponen cabelleras, a otros dientes, ojos, brazos y piernas postizas, y lo peor es que a muchos, con pretexto de que en tiempo que se escribían los libros a mano y faltaba la emprenta se cometían muchos errores, les cortan los dedos o las manos, diciendo que no son aquellas naturales, y les ponen otras, con que todos salen desfigurados de las suyas. Este atrevimiento es tal, que aun se adelantan a adivinar los conceptos no imaginados, y mudando las palabras, mudan los sentidos y taracean los libros. No me pareció que tenía seguras mis narices en aquella calle y saliendo della muy apriesa, dije a Polidoro que ya habíamos visto en la entrada de la ciudad ocupada en otros oficios esta misma gente. Respondióme con gracioso despacho: Críticos hay para todo».

Espero no haber merecido de la benevolencia de ustedes que me cuenten totalmente en la clase de los críticos que, con donaire tanto, fustigaba mi ilustre paisano Don Diego. 